\title{
Thermodynamic and experimental simulation of interactions in the Ta-ZnS system
}

\author{
(C) Lyudmila Yu. Udoeva, ${ }^{1 *}$ Sergey Agafonov, ${ }^{1+}$ and Sofia A. Petrova ${ }^{2}$ \\ ${ }^{1}$ Laboratory of Non-Ferrous Metals Pyrometallurgy. ${ }^{2}$ Laboratory of Physical Chemistry \\ Of Metallurgical Melts. FSBIS Institute of Metallurgy. Ural Branch of the Russian \\ Academy of Sciences.Amundsen St., 101. Yekaterinburg, 620016. Russia. \\ Phone:+7 (343) 232-90-81.E-mail: lyuud@yandex.ru
}

*Supervising author; ${ }^{+}$Corresponding author
Keywords: tantalum, zinc sulfide, sulfidization, thermodynamic simulation, phase formation.

\begin{abstract}
The article presents the results of studies to estimation the possibility of sulfiding of metallic tantalum by zinc sulfide in an inert atmosphere. To theoretically substantiate the possibility of the process, the HSC 6.12 Chemistry software package (Outotec) was used, which allows predicting the equilibrium composition of the interaction products. The Gibbs energies of possible reactions in the ZnS-Ta system are calculated, the optimum operating parameters of the process of complete transformation of metallic tantalum into $\mathrm{TaS}_{2}$ are determined. Experimental studies were carried out in a tubular furnace in a flow of an inert gas (helium) supplied through a closed loop of an alundum reactor. Components with different molar ratios compressed into tablets were kept at the temperature $1300{ }^{\circ} \mathrm{C}$ for 90 minutes. It has been found tantalum disulfide of two modifications (hexagonal and trigonal systems) and $\mathrm{Ta}_{5} \mathrm{~S}_{8}(14.1 \%)$ are formed at a stoichiometric $\mathrm{ZnS} / \mathrm{Ta}$ molar ratio of 2.0. Its subsulfides $\left(\mathrm{Ta}_{1.23} \mathrm{~S}_{2}, \mathrm{Ta}_{3.1} \mathrm{~S}_{6}, \mathrm{TaS}(\mathrm{y})\right)$, which are intermediate phases in the transformation of tantalum-to- $\mathrm{TaS}_{2}$, are formed if a sulfidizer is deficient. The identification of the phases and the estimation of their proportion in the sulfiding product were made by the full-profile analysis by Rietveld method. The experimental conditions did not reveal the formation of complex sulfides like the $\mathrm{Zn}_{\mathrm{x}} \mathrm{TaS}_{2}$, the formation of which is possible because of zinc intercalation between the layers of the tantalum disulfide basic structure of the crystal lattice.
\end{abstract}

\section{References}

[1] F.J. Di Salvo, G.W. Hull, L.H. Schwartz, J.M. Voorhoeve, J.V. Warszczak. Metal intercalation compounds of $\mathrm{TaS}_{2}$ : Preparation and properties. J. Chem. Phys. 1973. Vol.59. P.1922-1929.

[2] H. Wada, M. Onoda. On the preraration and structure of the compound $\mathrm{Ta}_{3} \mathrm{~S}_{1.8}$. Mater. Res. Bull. 1989. Vol.24. P.191-196.

[3] L.Yu. Udoeva, and V.M. Chumarev. Assessment of silicon purification possibility by chemical vapor transport reaction with zinc sulfide. Butlerov Communications. 2019. Vol.59. No.9. P.49-57. DOI: 10.37952/ROI-jbc-01/19-59-9-49

[4] M.N. Faraggi, X. Zubizarreta, V.M. Silkin, A. Arnau. On the stability of the electronic system in transition metal dichalcogenides. Journal of Phisics: Condensed Matter. 2016. Vol.28. № 18. P.1-6 DOI:10.1088/0953-8984/28/18/184004

[5] A.D. Vershinin, V.P. Mar'evich, V.M. Chumarev, E.N. Selivanov. Effect of tantalum on phase formation in the Fe-S system. Russian Journal of Inorganic Chemistry. 2007. Vol.52. No.9. P.1459-1463. (russian)

[6] NEW HSC CHEMISTRY - 6.1.: http://hsc-chemistry.net/index.html

[7] R.A. Isakova. Davlenie para sul'fidov cvetnyh metallov. Alma-Ata: AN KazSSR. 1963. 130p. (russian)

[8] B.V. Zuev, V.N. Nesterov. Vapor pressure of non-ferrous metal sulfides. Bulletin Academy of Sciences of the Kazakh SSR. A Series of Mining, Metallurgy, Construction and Building Materials. 1956. Vol.9. P.2630. (russian)

[9] F. Jellinek. The system tantalum-sulfur. J. Less-Common Met. 1962. Vol.4. No.9. P.9-15.

[10] A. Uells. Structural Inorganic Chemistry. Vol.2. Moscow: Mir. 1987. P.521-524. (russian)

[11] H.M. Rietveld. A Profile Refinement Method for Nuclear and Magnetic Structures. J. Appl. Crystallogr. 1969. Vol.2. P.65-71.

[12] DIFFRACPlus: TOPAS Bruker AXS GmbH, Ostliche. Rheinbruckenstraße 50, D-76187, Karlsruhe, Germany. 2008.

[13] W.P. Omloo, F. Jellinek. Intercalation compounds of alkali metals with niobium and tantalum dichalcogenides. J. Less-Common Met. 1970. Vol.20. P.121-129. 